\title{
GÊNEROS DE TEXTO NA BNCC: UM DIÁLOGO COM A PEDAGOGIA COM BASE EM GÊNEROS DA ESCOLA DE SYDNEY
}

\author{
TEXTUAL GENRES ON BNCC: A DIALOGUE WITH THE SYDNEY \\ SCHOOL GENRE-BASED PEDAGOGY
}

\author{
Heryzânya Alves Ramalho (IFRN) \\ heryzanya@hotmail.com \\ Orlando Vian Jr. (UNIFESP/CNPq) \\ vian.junior@unifesp.br \\ Jennifer Sarah Cooper (UFRN) \\ jennifersarahj@gmail.com
}

\begin{abstract}
RESUMO: Este artigo analisa orientações relacionadas aos gêneros de texto em todas as etapas da educação na Base Nacional Comum Curricular (BNCC) pela perspectiva da Pedagogia com base em Gêneros da Escola de Sydney (PGES) (MARTIN; ROSE, 2008; ROSE; MARTIN, 2012) e da Linguística Sistêmico-Funcional (HALLIDAY; MATTHIESSEN, 2014). Na análise, observamos que a PGES dialoga com as concepções de língua e de gênero nas quais a BNCC está fundamentada, podendo ser empregada, portanto, em todas as etapas da educação. Sugerimos, ainda, o uso da PGES associada à pedagogia crítica de Paulo Freire (VIAN JR.; FARIA, 2021) como suporte teórico-metodológico no trabalho com gêneros, visto que ambas atendem às recomendações da Base referentes ao desenvolvimento da autonomia e do pensamento crítico do aprendiz e à proposta de diminuição da desigualdade na aprendizagem, ainda que a organização do próprio documento possa divergir nesse ponto.
\end{abstract}

PALAVRAS-CHAVE: gêneros de texto; BNCC; Pedagogia com base em Gêneros da Escola de Sydney; Linguística Sistêmico-Funcional.

ABSTRACT: This article analyzes orientations related to textual genres in all levels of education in the BNCC (Brazilian National Common Core Curriculum) based on the Sydney School Genre-Based Pedagogy (SSGBP) (MARTIN; ROSE, 2008; ROSE; MARTIN, 2012), and on the Systemic Functional Linguistics (HALLIDAY; MATTHIESSEN, 2014). In the analysis, we observed that the SSGBP dialogues with the concepts of language and genre mentioned on the BNCC, thus, enabling the use of this pedagogy at all educational levels. We also suggest the use of the SSGBP allied with the critical pedagogy of Paulo Freire as a theoretical and methodological support for working with genres, for they meet the 
recommendations derived from the BNCC in terms of developing the learner's autonomy and critical thinking as well as the proposition of reducing learning inequality, notwithstanding that the document organization itself might diverge on this matter.

KEYWORDS: textual genres; BNCC; Sydney School Genre-Based Pedagogy; SystemicFunctional Linguistics.

\section{Introdução}

O ensino com base em gêneros de texto vem sendo abordado oficialmente no Brasil desde a sugestão dada nos Parâmetros Curriculares Nacionais (doravante PCNs) para que os gêneros fossem adotados como objetos de ensino (BRASIL, 1998). Essa coleção de documentos, assim como outros documentos derivados, ancoram-se, principalmente, na perspectiva de Vygotsky relacionada à aprendizagem e na concepção bakhtiniana de gênero (BORGES, 2012). A partir das discussões levantadas nesses dispositivos oficiais da educação, o trabalho com base em gêneros de texto na escola tem sido, cada vez mais, foco de diversos estudos científicos, além de ter influenciado na maneira com que os conteúdos dos materiais didáticos são construídos.

Szundy e Cristovão (2008) atentam para as questões político-ideológicas que envolvem a confecção de tais dispositivos, lembrando que as decisões relativas à educação no Brasil partem, primeiramente, do Ministério da Educação. O Ministério, por sua vez, delega a construção desses documentos a especialistas das respectivas áreas de atuação. Dessa maneira, "o sistema didático, constituído pelo triângulo didático professor/aluno/conteúdo, incorpora os conhecimentos do sistema educacional e do sistema de ensino [...]" (SZUNDY; CRISTOVÃO, 2008) com o intuito de que estes sejam adaptados à realidade das escolas e dos aprendizes.

Em termos oficiais, o dispositivo que estabelece as diretrizes da educação básica brasileira atualmente é a Base Nacional Comum Curricular (BNCC), vigente desde dezembro de 2018, após várias versões. Desenvolvido por especialistas de diversas áreas do conhecimento, o documento abarca tanto as diretrizes para a educação, fornecidas pela Lei de Diretrizes e Bases (LDB), como também os direcionamentos dados pelos PCNs e pelas Diretrizes Curriculares Nacionais (DCNs) (BRASIL, 2018). Nesse sentido, a BNCC continua com sua proposta de utilização de gêneros de texto em sala, especialmente no referente às disciplinas de línguas. 
Quanto ao documento, Szundy (2017) enfatiza que a Base possui caráter prescritivo sob a justificativa de que a aplicação de suas diretrizes quanto às práticas em sala de aula é fundamental na tentativa de diminuir a disparidade escolar no território brasileiro em termos curriculares e pedagógicos. Sendo assim, as escolhas de cunho teórico, metodológico e pedagógico das escolas e, consequentemente, dos professores, precisam estar alinhadas aos preceitos dispostos nesse documento oficial.

Por essa razão, e tendo em vista o grau de relevância desse documento para a educação básica brasileira, propomos, neste artigo de caráter bibliográfico, analisar as orientações dadas pela BNCC envolvendo o uso de gêneros de texto na escola. Para isso, ancoramo-nos nos estudos oriundos da Pedagogia com base em Gêneros da Escola de Sydney (PGES) (MARTIN; ROSE, 2008; ROSE; MARTIN, 2012) e, por conseguinte, nos princípios da Linguística Sistêmico-Funcional (LSF) (HALLIDAY, 1978, 1994; HALLIDAY, MATTHIESSEN, 2014), dada nossa experiência com essa abordagem ao longo dos anos e com o objetivo de promover discussões sobre como essas orientações podem ser relacionadas à proposta da PGES para a sala de aula.

Nesse intuito, iniciamos com uma apresentação da concepção da PGES sobre gênero e ensino de língua que, por sua vez, traz à tona conceitos-chave da LSF referentes à linguagem expostos na seção 1. A partir da exposição teórica, discutimos a proposta dessa pedagogia quanto às aulas na educação básica e também apresentamos a BNCC de forma sucinta para que, em seguida, possamos dar início à análise do documento. Por fim, apresentamos nossas considerações finais sobre as orientações dadas na Base e o seu possível diálogo com a PGES.

\section{A PGES e conceitos-chave da LSF}

A PGES, ou simplesmente Escola de Sydney (HYON, 1996; JOHNS, 2002; MARTIN; ROSE, 2008; ROSE; MARTIN, 2012), é o nome pelo qual ficou conhecida uma série de trabalhos envolvendo o ensino e a aprendizagem por meio de gêneros em escolas na Austrália. Essa pedagogia baseia-se nos pressupostos da LSF (HALLIDAY, 1978, 1994; HALLIDAY; MATTHIESSEN, 2014) e foca o trabalho de leitura e de produção de textos que instanciam gêneros fundamentais para o currículo escolar com o intuito de que todos os alunos, sem exceções, possam ter êxito acadêmico (ROSE; MARTIN, 2012).

A PGES compartilha a concepção de língua da LSF como um recurso sociossemiótico utilizado pelos usuários para criar e expressar sentidos em um dado contexto. Assim, estabelece-se uma relação dialética entre a língua e seus usuários de modo que esse 
relacionamento varia de acordo com o objetivo sociocomunicativo e o contexto em que a interação ocorre, conforme apontado por Halliday (1978). Nessa perspectiva, o objeto linguístico é analisado e descrito como um sistema complexo organizado em diferentes estratos. Ele também envolve metafunções específicas (HALLIDAY, 1994; HALLIDAY; MATTHIESSEN, 2014).

Embora os desdobramentos desses conceitos não sejam discutidos aqui, dado o foco deste texto $^{1}$, vale destacar que, uma vez que a PGES está ancorada nessa teoria linguística, o ensino de gêneros nessa pedagogia não pode ser dissociado da análise linguística, tanto no nível fonético, léxico-gramatical e semântico quanto no nível contextual. Por essa razão, a PGES propõe o ensino explícito da língua, o que significa dizer que essa abordagem envolve não apenas os aspectos relacionados aos gêneros que os textos instanciam, mas, também, os elementos linguísticos que efetivamente constroem os sentidos desses gêneros (MARTIN; ROSE, 2008).

$\mathrm{Na}$ perspectiva da PGES, os gêneros constituem "[...] processos sociais que se desenvolvem em etapas e que possuem um propósito [...]” (ROSE; MARTIN, 2012, p. 54, tradução nossa $)^{2}$. Assim, quando descrevemos o passo a passo da confecção de um produto ou apresentamos os passos necessários para a realização de determinado processo, seja com o intuito de compartilhar ou até mesmo de guardar essas informações, estamos instanciando, neste caso, o gênero procedimento. Na área acadêmica, por exemplo, quando abordamos uma questão social sobre a qual expomos diferentes perspectivas a respeito de um assunto, estamos tratando do gênero discussão (MARTIN; ROSE, 2008).

As etapas, por sua vez, funcionam como passos que o gênero precisa ter para ser identificado como tal. Elas podem, ainda, ser compostas por fases que possuem caráter opcional (MARTIN; ROSE, 2008; ROSE; MARTIN, 2012). O gênero discussão, por exemplo, apresenta três etapas obrigatórias: Problema, Lados e Resolução. Em relação à etapa Lados, as suas fases podem ser estabelecidas como lado1, lado2, lado $x$, conforme descreve Ramalho (2016), a partir dos aportes teóricos da PGES. Dessa maneira, as etapas e fases são compreendidas como componentes da estrutura esquemática dos exemplares de um determinado gênero. Vale ressaltar, portanto, que a estrutura esquemática consiste no modo com que o gênero se configura a partir da análise dos textos que o concretizam (MARTIN; ROSE, 2008).

\footnotetext{
${ }^{1}$ Remetemos os leitores não familiarizados com a teoria ou com essas noções para os trabalhos de Gouveia (2009) e Fuzer e Cabral (2014), que oferecem subsídios para que compreendamos os preceitos idealizados por Halliday.

${ }^{2}$ No trecho original: “[...] staged, goal-oriented, social processes [...]". 
Outro conceito pertinente aos gêneros de texto na perspectiva da PGES é o de famílias. Segundo Rose e Martin (2012), as famílias são compostas por gêneros que apresentam semelhanças entre si, principalmente no que diz respeito aos seus propósitos sociais. Os autores ainda apontam que essas famílias podem estar aliadas ao propósito de avaliar (família dos argumentos e das reações a textos), engajar (família das estórias) e informar (família das histórias, explicações, relatórios e procedimentos) (ROSE; MARTIN, 2012).

A partir dos pressupostos sistêmico-funcionais sobre gêneros de texto delineados em Halliday e Hasan (1989), a PGES sistematizou esses conhecimentos de modo que eles fossem abordados de forma didática em sala de aula, resultando, portanto, no Ciclo de Ensino e Aprendizagem (CEA), conforme exposto na Figura 1:

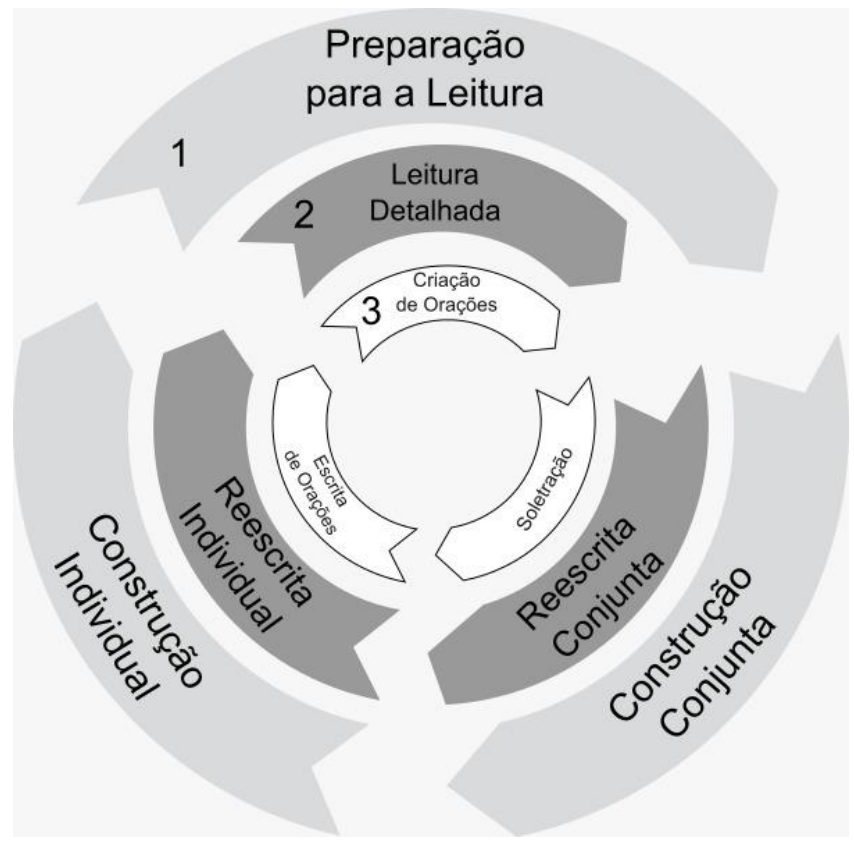

Figura 1 - Ciclo de ensino e aprendizagem da pedagogia com base em gêneros da escola de Sydney

Fonte: Traduzido e adaptado de Rose e Martin (2012, p. 161)

Nota-se que o ciclo apresenta diferentes estratégias para o ensino e aprendizagem de gêneros de texto em sala. Inicialmente, há a Preparação para Leitura, que envolve o levantamento de conhecimentos prévios dos alunos. Esse levantamento pode ser feito de diferentes maneiras, como, por exemplo, a partir de um exemplar do gênero a ser trabalhado. No entanto, essa estratégia também pode ser abordada tomando por base textos de diferentes 
naturezas (imagens, músicas, gráficos etc.) na discussão com os estudantes sobre a área, o tema de estudo ou sobre os elementos linguísticos do texto (ROSE, 2017).

A partir disso, o ensino com base em gêneros pode ser aprofundado por meio da realização de outras estratégias, as quais consistem em atividades linguísticas mais específicas, como a Leitura Detalhada, na qual são exercitadas a leitura e a compreensão das orações de determinado trecho do texto, e a Escrita de Orações, que envolve a criação de novas orações a partir de exemplos também associados ao texto, por exemplo.

Ocorre, na sequência, a Construção Conjunta de um novo exemplar de texto que instancia o gênero em foco. Isso significa que a realização da tarefa envolve tanto a turma (ao dar ideias para a nova produção textual) quanto o professor (ao trabalhar com as sugestões recebidas na construção do texto). É importante que o texto seja escrito no quadro para facilitar a visualização e a interação entre todos.

Há ainda o momento da Construção Individual, no qual o aluno produz o seu próprio exemplar individualmente. Ambas as estratégias de construção textual podem ser seguidas de momentos de reconstrução desses exemplares como formas de aprimorar os conhecimentos linguísticos adquiridos sobre o gênero abordado. É necessário, contudo, ressaltar que as estratégias do CEA podem ser ordenadas conforme a necessidade do professor e da turma (ROSE; MARTIN, 2012). Isso significa que, embora o ciclo seja apresentado como um sequenciamento para as estratégias, sua aplicação é flexível e adaptável à realidade da sala de aula (ROSE, MARTIN, 2012; FARIA, 2019).

Ressaltamos, ainda, que o CEA foi planejado com o intuito de desenvolver a autonomia dos alunos quanto aos gêneros de texto. Isso significa que o professor media as atividades de reconhecimento, a análise e a produção de textos de determinado gênero em cooperação com a turma, para que, pouco a pouco, cada aluno se sinta mais confiante para produzir seus exemplares individualmente. Por essa razão, a PGES entende que esse trabalho linguístico deve ocorrer de forma explícita, uma vez que os alunos precisam estar cientes das delimitações e das possibilidades que cada gênero abarca (ROSE; MARTIN, 2012).

\section{A BNCC, a aprendizagem e as competências}

Como o próprio nome sugere, o principal objetivo da BNCC é estabelecer orientações e diretrizes comuns a todas as escolas do Ensino Básico (EB) a nível nacional (BRASIL, 2018). Sendo assim, compreende-se que a justificativa para a criação do documento é nivelar a educação básica no território brasileiro com o intuito de garantir um ensino mais igualitário. 
Para esse fim, foram reunidos grupos de especialistas das diversas áreas do conhecimento, os quais contribuíram, cada um em sua área de estudo, para a construção da BNCC. Em suma, o documento teve três versões homologadas, com a inclusão da seção do Ensino Médio (EM) na última versão. Por esse motivo, as discussões levantadas aqui são referentes à versão final da Base (BRASIL, 2018).

Quanto à sua organização, a BNCC estrutura-se em três etapas: a etapa da Educação Infantil (EI), a etapa do Ensino Fundamental (EF) e, por fim, a etapa do EM. Em todas elas, são trabalhados dois conceitos-chave em cada uma das áreas do conhecimento abordadas: as concepções de aprendizagens essenciais e as de competências.

De acordo com o documento, as aprendizagens essenciais dizem respeito aos conhecimentos básicos que devem ser desenvolvidos por todos os alunos do EB. Em relação às competências, afirma-se que “[...] as aprendizagens essenciais definidas na BNCC devem concorrer para assegurar aos estudantes o desenvolvimento de dez competências gerais, que consubstanciam, no âmbito pedagógico, os direitos de aprendizagem e desenvolvimento." (BRASIL, 2018, p. 8).

As dez competências gerais da educação básica definidas pela BNCC compreendem o que deve ser aprendido e, de forma resumida, incluem: (i) conhecimento, (ii) pensamento científico, crítico e criativo, (iii) repertório cultural, (iv) comunicação, (v) cultura digital, (vi) trabalho e projeto de vida, (vii) argumentação, (viii) autoconhecimento e autocuidado, (ix) empatia e cooperação, e (x) responsabilidade e cidadania. Essas competências envolvem, entre outros fatores, o conhecimento de diferentes linguagens e formas de expressão de forma autônoma, crítica e consciente. Além disso, a educação deve estar pautada na ciência, e também no uso de diferentes tecnologias de informação e da comunicação.

Nesse sentido, observamos que é possível estabelecer um diálogo direto entre a PGES e algumas dessas competências. Em relação à competência (ii), podemos associá-la a gêneros da família do informar, como explicações, relatórios e procedimentos, visto que podem ser usados para a resolução de problemas. As competências (iv) e (v), por sua vez, estão relacionadas à expressão em diferentes linguagens e ao caráter multimodal dos textos, os quais também são abordados na PGES. Por fim, a competência (vii) está relacionada diretamente com os gêneros da família dos argumentos, como exposições e discussões, amplamente desenvolvidas na PGES.

A partir dessas competências gerais, cada disciplina ou área do conhecimento apresenta, por sua vez, as suas competências específicas que envolvem o desenvolvimento de determinadas habilidades (BRASIL, 2018). Nesse sentido, a competência de ordem 
linguística está aliada, também, ao domínio de gêneros de texto de diferentes esferas do conhecimento. Portanto, na próxima seção, analisamos as orientações referentes aos gêneros de texto, levando em consideração, também, as habilidades que estão associadas a eles.

\section{Gêneros de texto na BNCC}

Nesta seção, observamos as orientações da BNCC sobre o ensino e a aprendizagem por meio de gêneros nas diferentes etapas da educação de modo a validar ou não a aplicação da PGES em sala conforme os termos estabelecidos pela Base. Para esse fim, a seção está organizada em três subseções referentes aos níveis do EB: primeiramente, tratamos dos gêneros no EI, depois adentramos o nível do EF e, finalmente, abordamos o EM.

\subsection{Gêneros na educação infantil}

O item lexical gêneros é constante no documento da Base. Ele está presente em todas as etapas da educação, do EI ao EM, sendo enfatizado como elemento fundamental na aprendizagem escolar, como indica o excerto a seguir, na primeira ocorrência do termo na Base:

Desde cedo, a criança manifesta curiosidade com relação à cultura escrita: ao ouvir e acompanhar a leitura de textos, ao observar os muitos textos que circulam no contexto familiar, comunitário e escolar, ela vai construindo sua concepção de língua escrita, reconhecendo diferentes usos sociais da escrita, dos gêneros, suportes e portadores. Na Educação Infantil, a imersão na cultura escrita deve partir do que as crianças conhecem e das curiosidades que deixam transparecer. (BRASIL, 2018, p. 42).

Nesse trecho, observa-se que ocorre uma referência ao reconhecimento de gêneros de texto, dentre outros fatores, como porta de entrada para o universo da escrita. Desse modo, orienta-se que a introdução de novos gêneros em sala leve em consideração os conhecimentos prévios dos alunos, bem como a sua curiosidade pelo novo. Tal recomendação é reforçada na Figura 2, com a exposição dos objetivos de aprendizagem e desenvolvimento no EI. Cabe ressaltar, ainda, que o termo gêneros foi destacado na figura para facilitar a visualização de recorrências. 


\begin{tabular}{|c|c|c|}
\hline $\begin{array}{l}\text { Bebés (zero a } 1 \text { ano e } \\
6 \text { meses) }\end{array}$ & $\begin{array}{l}\text { Crianças bem pequenas (1 ano } \\
\text { e } 7 \text { meses a } 3 \text { anos e } 11 \text { meses) }\end{array}$ & $\begin{array}{l}\text { Crianças pequenas ( } 4 \text { anos a } \\
5 \text { anos e } 11 \text { meses) }\end{array}$ \\
\hline $\begin{array}{l}\text { (EIO1EFO6) } \\
\text { Comunicar-se com } \\
\text { outras pessoas usando } \\
\text { movimentos, gestos, } \\
\text { balbucios, fala e outras } \\
\text { formas de expressão. }\end{array}$ & $\begin{array}{l}\text { (EIO2EFO6) } \\
\text { Criar e contar histórias } \\
\text { oralmente, com base em } \\
\text { imagens ou temas sugeridos. }\end{array}$ & $\begin{array}{l}\text { (ElO3EFO6) } \\
\text { Produzir suas próprias } \\
\text { histórias orais e escritas } \\
\text { (escrita espontănea), em } \\
\text { situaçōes com funçăo social } \\
\text { significativa. }\end{array}$ \\
\hline $\begin{array}{l}\text { (EIO1EFO7) } \\
\text { Conhecer e manipular } \\
\text { materiais impressos e } \\
\text { audiovisuais em diferentes } \\
\text { portadores (livro, revista, } \\
\text { gibi, jornal, cartaz, CD, } \\
\text { tablet etc.). }\end{array}$ & $\begin{array}{l}\text { (EIO2EFO7) } \\
\text { Manusear diferentes } \\
\text { portadores textuais, } \\
\text { demonstrando reconhecer } \\
\text { seus usos sociais. }\end{array}$ & $\begin{array}{l}\text { (ElO3EFO7) } \\
\text { Levantar hipóteses sobre } \\
\text { gêneros textuais veiculados } \\
\text { em portadores conhecidos, } \\
\text { recorrendo a estratégias de } \\
\text { observação gráfica e/ou de } \\
\text { leitura. }\end{array}$ \\
\hline $\begin{array}{l}\text { (EIO1EFO8) } \\
\text { Participar de situações } \\
\text { de escuta de textos } \\
\text { em diferentes gêneros } \\
\text { textuais (poemas, } \\
\text { fábulas, contos, receitas, } \\
\text { quadrinhos, anúncios etc.). }\end{array}$ & $\begin{array}{l}\text { (EIO2EFO8) } \\
\text { Manipular textos e participar } \\
\text { de situaçōes de escuta para } \\
\text { ampliar seu contato com } \\
\text { diferentes gêneros textuais } \\
\text { (parlendas, histórias de } \\
\text { aventura, tirinhas, car tazes de } \\
\text { sala, cardápios, notícias etc.). }\end{array}$ & $\begin{array}{l}\text { (EIO3EFO8) } \\
\text { Selecionar livros e textos } \\
\text { de géneros conhecidos para } \\
\text { a leitura de um adulto e/ou } \\
\text { para sua própria leitura } \\
\text { (partindo de seu repertório } \\
\text { sobre esses textos, como a } \\
\text { recuperação pela memória, } \\
\text { pela leitura das ilustraçōes } \\
\text { etc.). }\end{array}$ \\
\hline $\begin{array}{l}\text { (EIO1EFO9) } \\
\text { Conhecer e manipular } \\
\text { diferentes instrumentos e } \\
\text { suportes de escrita. }\end{array}$ & $\begin{array}{l}\text { (EIO2EFO9) } \\
\text { Manusear diferentes } \\
\text { instrumentos e suportes de } \\
\text { escrita para desenhar, traçar } \\
\text { letras e outros sinais gráficos. }\end{array}$ & $\begin{array}{l}\text { (ElO3EFO9) } \\
\text { Levantar hipóteses em } \\
\text { relação à linguagem escrita, } \\
\text { realizando registros de } \\
\text { palavras e textos, por meio } \\
\text { de escrita espontânea. }\end{array}$ \\
\hline
\end{tabular}

Figura 2 - Objetivos de aprendizagem e desenvolvimento na educação infantil da BNCC Fonte: BNCC (BRASIL, 2018, p. 50, grifos nossos)

Ao esquematizar a aprendizagem de conhecimentos em termos de faixa etária e de acordo com a evolução do aprendizado, podemos relacionar esse modo de organização à ideia da zona de desenvolvimento proximal (ZDP) de Vygotsky (2012). Também referida na PGES (ROSE; MARTIN, 2012), a ZDP envolve a construção de saberes de modo que se parte do conhecimento já estabelecido para uma nova forma de conhecimento ${ }^{3}$.

No caso da Figura 2, percebemos que a utilização de gêneros de texto, dessa vez, está aliada à habilidade da compreensão oral e que se orienta a leitura dos textos por parte de um adulto (o professor, no caso) e/ou pelo próprio aluno durante as aulas. No caso da PGES, esse processo de leitura do texto aliado à sua compreensão envolve justamente a estratégia da Leitura Detalhada. Nesse momento do CEA, o professor pode ler o texto em voz alta, seguido

\footnotetext{
${ }^{3}$ Além de fundamentada nos preceitos da LSF (HALLIDAY, 1994; HALLIDAY; MATTHIESSEN, 2014), a PGES também faz referência à psicologia do desenvolvimento de Vygotsky (2012). No entanto, segundo Rose e Martin (2012), uma de suas principais fontes de inspiração está nos estudos de sociologia educacional de Basil Bernstein $(1979,1996)$, que compreende o sistema educacional como sendo um "dispositivo pedagógico" com diferentes níveis de atuação.
} 
em outro momento pelos próprios alunos, além de trabalhar a compreensão oral da turma por meio da discussão sobre as escolhas linguísticas e os sentidos realizados nos trechos lidos (ROSE; MARTIN, 2012).

\subsection{Gêneros no ensino fundamental}

A apresentação das perspectivas da Base sobre linguagem, texto e gênero ocorre na subseção da disciplina de língua portuguesa (LP) do EF. Desse modo, assim como os PCNs nos quais está fundamentada, a BNCC assume uma “[...] perspectiva enunciativo-discursiva de linguagem" (BRASIL, 2018, p. 67), que compreende o seu objeto como "[...] uma forma de ação interindividual orientada para uma finalidade específica: um processo de interlocução que se realiza nas práticas sociais [...]" (BRASIL, 1998, p. 20). Percebe-se, portanto, que esta concepção linguística dialoga com a LSF no sentido de que possui uma visão da linguagem como prática social. O documento ainda aponta o texto como unidade de trabalho central envolvendo o uso de gêneros e outras práticas de linguagem (BRASIL, 2018).

No caso da subseção de LP para o EF, há um adendo relacionado aos gêneros de texto que devem ser abordados em sala. Embora os gêneros tradicionais nas aulas de LP necessitem ser trabalhados, “[...] tais como notícia, reportagem, entrevista, artigo de opinião, charge, tirinha, crônica, verbete de enciclopédia, artigo de divulgação científica etc.[...]” (BRASIL, 2018, p. 69), há a solicitação no documento da Base para que o educador contemple também os letramentos ${ }^{4}$ digitais, os quais fazem parte do cotidiano dos estudantes, como vídeominuto, gifs e memes, por exemplo. Em relação ao EF, os gêneros encontram-se aliados às habilidades de leitura, de oralidade e de escrita e devem estar contextualizados durante o trabalho em sala.

Com base na abordagem vygotskyana de ensino, a BNCC recomenda que "a demanda cognitiva das atividades de leitura deve aumentar progressivamente desde os anos iniciais do Ensino Fundamental até o Ensino Médio" (BRASIL, 2018, p. 75), tanto no que tange a diversidade de gêneros de texto trabalhados como também a sua complexidade em termos de vocábulos, estrutura sintática, temática etc. Além disso, há a sugestão na Base de que outros gêneros que não se encontram nas recomendações do documento também sejam utilizados em sala, podendo ser aplicados em qualquer ano escolar a depender do julgamento do professor.

\footnotetext{
${ }^{4}$ De acordo com Halliday (1996), o letramento envolve o domínio da língua escrita no sentido de saber onde, como e quando empregar os padrões léxico-gramaticais nos textos escritos. Portanto, na visão do autor, ser letrado significa ser capaz de participar dos processos sociais de forma eficaz no uso da linguagem escrita.
} 
No âmbito da PGES, é possível relacionar os gêneros indicados na BNCC aos propósitos sociais de engajar, informar e avaliar apontados por Rose e Martin (2012), de modo a observar como essas propostas são abordadas pelos autores nos diferentes segmentos escolares.

Embora a discussão sobre gêneros de texto para o EF esteja mais concentrada na disciplina de LP, algumas recorrências do termo são encontradas, ainda, nas disciplinas de língua inglesa (LI) e geografia. Na LI, permanece a ideia de abordagem de gêneros tradicionais utilizados na escola, bem como os de caráter digital. Menciona-se, também, no texto da Base, a ideia de fazer trabalhos interdisciplinares tendo em vista os gêneros utilizados em sala. No caso da geografia, faz-se menção à necessidade do uso de gêneros aliados à cartografia e a geotecnologias em sala.

Tendo em vista o uso de gêneros de texto em diferentes disciplinas, sugerimos que as suas práticas de leitura e de produção estejam alinhadas a letramentos múltiplos que envolvam não somente a construção esquemática e o manuseio linguístico dos textos, mas também outros elementos pertinentes às matérias, como dados cartográficos e instrumentos geológicos no caso da geografia, por exemplo. Além disso, conforme aponta Faria (2019) em seu trabalho, o CEA proposto pela PGES pode também ser utilizado para promover o letramento crítico dos alunos de modo que tais conhecimentos sejam relacionados, ainda, a letramentos do seu cotidiano. Dentre as várias possibilidades, isso pode ser feito, especialmente, no momento de Preparação para a leitura, como a autora sugere (FARIA, 2019), para relacionar o tema sobre o qual será baseada a escrita e os posicionamentos dos estudantes sobre ele, dentre outras possibilidades que fogem ao escopo deste texto.

\subsection{Gêneros no ensino médio}

Na subseção da disciplina de LP para o EM, são dadas algumas orientações relacionadas aos gêneros de texto, as quais podem ser observadas no trecho a seguir:

Ao chegar ao Ensino Médio, os estudantes já têm condições de participar de forma significativa de diversas práticas sociais que envolvem a linguagem, pois, além de dominarem certos gêneros textuais/discursivos que circulam nos diferentes campos de atuação social considerados no Ensino Fundamental, eles desenvolveram várias habilidades relativas aos usos das linguagens. Cabe ao Ensino Médio aprofundar a análise sobre as linguagens e seus funcionamentos, intensificando a perspectiva analítica e crítica da leitura, escuta e produção de textos verbais e multissemióticos, e alargar as referências estéticas, éticas e políticas que cercam a produção e recepção de discursos, ampliando as possibilidades de fruição, de construção e produção de conhecimentos, de compreensão crítica e intervenção na realidade e de participação 
social dos jovens, nos âmbitos da cidadania, do trabalho e dos estudos. (BRASIL, 2018, p. 498, grifo original).

De acordo com esse excerto da BNCC, está subentendido que, no âmbito do EM, os alunos já estão familiarizados com vários gêneros indicados na seção do EF. Observa-se também que a Base enfatiza a importância de trabalhar a compreensão crítica e a participação social dos aprendizes por meio dos gêneros.

No caso da PGES, a sua proposta reflete diretamente na diminuição das desigualdades sociais $^{5}$ no ambiente escolar por meio da inclusão geral dos alunos, de modo que todos possam ser bem-sucedidos no meio acadêmico. Nesse sentido, essa pedagogia também se encontra configurada de maneira que a intervenção do professor nas atividades propostas seja reduzida progressivamente até que o aprendiz exerça completa autonomia nas suas produções (MARTIN; ROSE, 2008; ROSE; MARTIN, 2012). Esse estímulo à participação de todos, de forma igualitária, no estudo e na produção de gêneros de texto dos mais variados campos de atuação existentes pode ser aliado a outras propostas pedagógicas que visem não somente a compreensão, mas também o posicionamento crítico, como prega a pedagogia crítica de Paulo Freire (VIAN JR.; FARIA, 2021), por exemplo.

Em relação aos gêneros de texto em si, é apontado na BNCC que o repertório dos alunos deve ser aumentado não só em termos de variedade, mas também no que tange a complexidade esquemática e temática de gêneros já conhecidos por eles. Nesse sentido, os campos de atuação social que os professores trabalham em sala são ampliados na seção do EM (campo midiático, campo de pesquisa científica, campo mercadológico etc.). Desse modo, os gêneros propostos para a disciplina de LP no EM são discutidos de acordo com esses campos de atuação, conforme ilustra a Figura 3:

\footnotetext{
${ }^{5}$ É importante lembrar que a PGES teve início a partir de estudos referentes às disparidades no desempenho de alunos das escolas australianas, o que incluía, principalmente, estudantes de origem aborígene e imigrantes.
} 


\begin{tabular}{|c|c|c|}
\hline \multicolumn{2}{|c|}{ ENSINO FUNDAMENTAL } & \multirow[t]{2}{*}{ ENSINO MÉDIO } \\
\hline ANOS INICIAIS & ANOS FINAIS & \\
\hline $\begin{array}{l}\text { Campo da vida } \\
\text { cotidiana }\end{array}$ & & Campo da vida pessoal \\
\hline $\begin{array}{l}\text { Campo } \\
\text { artistico-literário }\end{array}$ & Campo artístico-literário & Campo artístico-literário \\
\hline $\begin{array}{l}\text { Campo das práticas de } \\
\text { estudo e pesquisa }\end{array}$ & $\begin{array}{l}\text { Campo das práticas de } \\
\text { estudo e pesquisa }\end{array}$ & $\begin{array}{l}\text { Campo das práticas de } \\
\text { estudo e pesquisa }\end{array}$ \\
\hline \multirow[t]{2}{*}{ Campo da vida pública } & Campo jornalístico-midiático & Campo jornalístico-midiático \\
\hline & $\begin{array}{l}\text { Campo de atuação na vida } \\
\text { pública }\end{array}$ & $\begin{array}{l}\text { Campo de atuação na vida } \\
\text { pública }\end{array}$ \\
\hline
\end{tabular}

Figura 3 - Campos de atuação social propostos pela BNCC

Fonte: BNCC (BRASIL, 2018, p. 501)

No campo jornalístico-midiático, alguns exemplos de gêneros indicados pela BNCC, mas que não figuram na PGES, são: reportagem multimidiáticas, documentários, ensaios e vlogs de opinião. No campo artístico-literário, os gêneros explicitados são: resenha, vlogs e podcasts literários, paródias, estilizações, fanfics, dentre outros. No campo da vida pessoal, os gêneros expostos são: apresentações pessoais, relatos autobiográficos, almanaques, fanzines etc. No campo de atuação na vida pública, alguns dos gêneros apresentados são: discussões orais, debates, leis, projetos de lei e estatutos. Por fim, no campo das práticas de estudo e pesquisa, os gêneros tratados são: apresentação oral, palestra, mesa-redonda, debate, artigo de divulgação científica, artigo científico, artigo de opinião, dentre outros (BRASIL, 2018).

É importante lembrar, nessa discussão, que os gêneros propostos na PGES e apresentados por Martin e Rose (2008) e Rose e Martin (2012) dizem respeito ao currículo escolar australiano. Por esse motivo, é fundamental atentar-se aos gêneros de texto indicados nos documentos orientadores da educação brasileira, como a BNCC, para que o ensino com base em gêneros ocorra de maneira contextualizada. Assim, é possível estabelecer diálogos entre os gêneros apontados na Base e as famílias propostas pela tipologia dos gêneros da PGES (ROSE; MARTIN, 2012) como, por exemplo, as histórias (campo jornalísticomidiático e campo da vida pessoa), as estórias (campo artístico-literário) e os argumentos (campo de atuação na vida pública e campo das práticas de estudo e pesquisa).

Em sequência à exposição desses campos de atuação, são apresentadas, ainda, na BNCC, as habilidades que devem ser desenvolvidas em cada um deles nas disciplinas de LP. Portanto, de modo geral, o trabalho com base em gêneros de texto nos campos abordados deve estar aliado a análises: do contexto sócio-histórico de produção dos textos; da Organon, Porto Alegre, v. 36, n. 71, p. 217-234, jan./jun. 2021. 
composição estrutural e do estilo dos gêneros; das relações de intertextualidade e interdiscursividade referentes aos textos abordados e dos recursos léxico-gramaticais e sintáticos empregados. Além disso, é sempre ressaltado na BNCC o trabalho de cunho crítico, envolvendo análises e discussões que partem de questões linguísticas a problemáticas de ordem contextual e social.

Tendo em vista essas orientações, reiteramos o emprego da PGES nesse contexto visto que a pedagogia consiste não apenas no trabalho com base em gêneros de texto, mas no ensino explícito dos recursos linguísticos que envolvem a sua produção - em associação a uma pedagogia de cunho crítico, ou seja, uma pedagogia que possa conectar o conhecimento linguístico a questões de caráter social, político e ideológico mais amplas e sensíveis aos contextos.

No caso de outras disciplinas da área de linguagem no EM, é preciso ressaltar que elas não dispõem de subseções próprias, tendo, portanto, as orientações resumidas aos direcionamentos gerais da área. Desse modo, nota-se que as seções dedicadas ao EM são mais restritas e, portanto, menos detalhadas.

Por essa razão, pode-se dizer que os conhecimentos e habilidades a serem trabalhadas pelos professores nessa última etapa do EB não são o foco do documento, visto que não há uma organização didática quanto aos assuntos e tópicos a serem abordados nas outras disciplinas da área: há apenas a explicitação das competências que devem ser adquiridas em cada campo do conhecimento no EM e a indicação de gêneros de texto por nome, sem maiores detalhamentos. Assim, parte-se do pressuposto que os professores sabem identificar os gêneros apontados e que também reconhecem as diferenças entre eles.

Também é necessário enfatizar a diferença nos tratamentos dados a disciplinas da mesma área, bem como ao modo desigual com que EI, EF e, principalmente, o EM são abordados. Por conseguinte, as orientações sobre gêneros seguem o mesmo padrão irregular: concentram-se nas disciplinas de LP, em termos de detalhamento e importância dada, em detrimento de outras disciplinas de línguas. Assim sendo, não se pode deixar de questionar a coerência na construção da Base quanto ao objetivo proposto de promover a diminuição da desigualdade na escola, uma vez que nem mesmo às disciplinas e níveis é dado o mesmo grau de importância no documento. 


\section{Considerações finais}

Com base na análise apresentada neste artigo sobre o modo como os gêneros de texto são abordados na BNCC, pode-se assumir que a perspectiva linguística adotada nesse documento orientador da educação dialoga com a LSF no sentido de que também compreende a linguagem como produto das práticas sociais e reconhece o gênero, por conseguinte, como elemento fundamental para que tais práticas se realizem.

Observa-se, também, que a Base assume a concepção vygostkyana da ZDP, na qual novos conhecimentos são adquiridos a partir do conhecimento previamente adquirido (VYGOSTKY, 2012). Nesse sentido, a PGES se aproxima mais uma vez da perspectiva educacional da Base, visto que utiliza o mesmo fundamento na implantação do CEA, embora incorpore outras teorias e autores sensíveis ao contexto australiano para o qual a proposta foi elaborada.

É importante salientar, ainda, que as primeiras orientações relacionadas ao ensino e aprendizagem com base em gêneros iniciam-se na EI seguindo até o EM, conforme preceitua a PGES (ROSE; MARTIN, 2012). Entretanto, é preciso lembrar que essa pedagogia tem como base o currículo escolar australiano e os gêneros que circulam naquele contexto, sendo, portanto, necessário realizar adaptações que estejam de acordo com as orientações curriculares brasileiras.

No caso da BNCC, observa-se que o ensino por meio de gêneros de texto é enfatizado em quase sua totalidade nas disciplinas de línguas, o que difere da visão transdisciplinar da pedagogia em foco. De qualquer maneira, há sugestões na própria Base sobre o ensino interdisciplinar com gêneros, tendo em vista as necessidades dos alunos de acordo com o nível escolar em que se encontram. Assim, abrem-se portas para que projetos dessa natureza ocorram de forma mais frequente no ambiente escolar.

Dadas as discussões levantadas aqui, sugerimos a PGES como ferramenta de apoio teórico-metodológico no trabalho com gêneros em qualquer uma (ou em todas) das etapas do $\mathrm{EB}$, pois ela atende às expectativas da Base quanto à forma de ensino e aos objetivos propostos em termos de ensino e aprendizagem com base em gêneros. Nesse sentido, propõese, ainda, a adoção da PGES em conjunto com uma pedagogia de cunho crítico, como a proposta por Paulo Freire (VIAN JR.; FARIA, 2021), de modo a fortalecer os princípios e metas citados no documento, principalmente no que tange ao desenvolvimento da consciência crítica e atuação na sociedade, bem como na construção de uma autonomia responsável e ética. 
Em relação ao emprego da PGES e, consequentemente, do CEA, é preciso salientar que ambos não devem ser resumidos a atividades de cunho estritamente linguístico. Isto é, seu uso pode ser ampliado a outros tipos de conhecimentos das mais diversas áreas, uma vez que essa pedagogia pode ser trabalhada em associação com outras propostas pedagógicas que comuniquem o mesmo objetivo de auxiliar o aluno a agir de forma crítica em qualquer esfera social (FARIA, 2019).

Finalmente, uma crítica feita à Base enquanto documento orientador consiste na visível diferença entre os níveis de detalhamento e de orientações empregados nas diversas etapas da EB. Nota-se que as disciplinas e os anos do EF são mais ricos em termos de direcionamentos e de organização didático-temática, diferentemente do EM, no qual não há esquematização dos conhecimentos envolvidos para cada disciplina, apenas orientações relacionadas às competências que devem ser desenvolvidas em cada área do conhecimento.

No que concerne o ensino com base em gêneros de texto, ocorre a mesma situação: há um suporte teórico-metodológico mais significativo no EF, o que pode ser visto como maior liberdade didática dada ao professor do EM ou como possível relaxamento das orientações na construção final do documento. Em termos de disciplinas, nota-se também que a disciplina de LP concentra os direcionamentos referentes a gêneros em todos os níveis abordados no documento em detrimento das outras disciplinas.

A partir dessas observações realizadas sob a perspectiva da PGES, pode-se assumir, portanto, que o tratamento diferenciado com que as disciplinas e níveis da EB são abordados na BNCC não condiz com o objetivo de diminuição da desigualdade escolar enfatizado no documento.

\section{REFERÊNCIAS}

BERNSTEIN, B. Pedagogy, Symbolic Control and Identity: theory, research, critique. London: Taylor and Francis, 1996.

BERNSTEIN, B. The new pedagogy: sequencing. In: MANNING-KEEPES, J.; KEEPS, B. D. (ed.). Language in Education: the LDP Phase 1. Canberra: Curriculum Development Centre, 1979. p. 293-302.

BORGES, F. G. B. Os gêneros textuais em cena: uma análise crítica de duas concepções de gêneros textuais e sua aceitabilidade na educação no Brasil. Revista Brasileira de Linguística Aplicada, Belo Horizonte, v. 12, n. 1, p. 119-140, 2012. 
BRASIL. Base Nacional Comum Curricular: Ensino Médio. Brasília, DF: MEC, 2018.

BRASIL, Ministério da Educação e do Desporto. Parâmetros Curriculares Nacionais. Brasília, DF: 1998.

FARIA, F. D. A Modalidade na Competência $V$ do ENEM: a aula de produção textual como prática de letramento crítico sob a perspectiva sistêmico-funcional. 2019. 167 f. Dissertação (Mestrado em Letras) - Programa de Pós-graduação em Letras, Universidade Federal de São Paulo, São Paulo, 2019.

FUZER, C.; CABRAL, S. R. S. Introdução à gramática sistêmico-funcional em língua portuguesa. Campinas: Mercado de Letras, 2014.

GOUVEIA, C. A. M. Texto e gramática: uma introdução à Linguística Sistêmico-Funcional. Revista Matraga, Rio de Janeiro, v. 16, n. 24, p. 13-47, jan./jun. 2009.

HALLIDAY, M. A. K. Language as social semiotic: the social interpretation of language and meaning. London: Edward Arnold, 1978.

HALLIDAY, M. A. K. An Introduction to Functional Grammar. 2. ed. London: Edward Arnold, 1994.

HALLIDAY, M. A. K. Literacy and linguistics: a functional perspective. In: HASAN, R.; WILLIAMS, G. (ed.). Literacy in society. London: Longman, 1996. p. 97-130.

HALLIDAY, M. A. K.; HASAN, R. Language, context, and text: aspects of language in a social-semiotic perspective. Oxford: Oxford University Press, 1989.

HALLIDAY, M. A. K.; MATTHIESSEN, C. M. I. M. Halliday's Introduction to Functional Grammar. 4. ed. New York: Routledge, 2014.

HYON, S. Genre in Three Traditions: implications for ESL. TESOL Quarterly, [s. l.], v. 30, n. 4, p. 693-722, 1996.

JOHNS, A. M. Genre in the classroom - multiple perspectives. Mahwah, NJ: Lawrence Erlbaum Associates, 2002.

MARTIN, J. R.; ROSE, D. Genre Relations: mapping culture. London: Equinox, 2008.

RAMALHO, H. A. Aspectos da Transitividade em Textos Argumentativos de Alunos de Inglês: um estudo sistêmico-funcional. 2016. 125 f. Dissertação (Mestrado em Estudos da Linguagem) - Programa de Pós- Graduação em Estudos da Linguagem, Universidade Federal do Rio Grande do Norte, Natal, 2016.

ROSE, D. Reading to Learn: preparing for reading and writing. v. 1. Australia: [s. n.], 2017.

ROSE, D.; MARTIN, J. R. Learning to write, reading to learn - Genre, knowledge and pedagogy in the Sydney School. Sheffield; Bristol: Equinox, 2012. 
SZUNDY, P. T. C. A base nacional comum curricular: implicações para a formação de professores/as de línguas(ens). In: MATEUS, E.; TONELLI, J. R. A. Diálogos

(im)pertinentes entre formação de professores e aprendizagem de línguas. São Paulo:

Blucher, 2017. p. 77-98.

SZUNDY, P. T. C.; CRISTOVÃO, V. L. C. Projetos de formação pré-serviço do professor de língua inglesa: sequências didáticas como instrumento no ensino-aprendizagem. Revista Brasileira de Linguística Aplicada, Belo Horizonte, v. 8, n.1, p. 115-138, 2008.

VIAN JR., O.; FARIA, F. D. Genre-based pedagogy in Paulo Freire's country: teaching Brazilian students to write essays for the national high school exam. Íkala, Medellín, v. 26, n.1, p. 61-76, jan./abr. 2021.

VYGOTSKY, L. S. Thought and Language. Cambridge: MIT Press, 2012.

Artigo submetido em: 04 abr. 2021

Aceito para publicação em: 10 jun. 2021

DOI: http://dx.doi.org/10.22456/2238-8915.112733 